\title{
ESTADO ACTUAL DEL CUIDADO INTENSIVO EN COLOMBIA
}

\author{
Mario Gómez Duque MD*
}

a medicina crítica, aunque joven, es una disciplina que en nuestro medio ha tenido un desarro11 vertiginoso debido a los cambios normativos en la salud, construidos con el sano argumento del mejoramiento de la calidad. Los aumentos de cobertura no solo se han limitado al número de cubículos; la reserva presupuestal ha convertido estas áreas en buenas unidades de negocio para las instituciones y todas estas circunstancias permiten hoy disponer de más de 4.500 camas en el país.

Es lamentable que los ajustes administrativos y la cobertura asistencial no han crecido en forma paralela y esto amenaza la especialidad en su esencia, que es la prestación de servicios de manera integral y armónica con cada uno de sus componentes: tecnológico, locativo, asistencial y humano. Desde su origen la situación es preocupante, pues en la actualidad vemos como los entes de control se esmeran en vigilar los estándares de calidad del recurso tecnológico o "el ángulo perfecto de las mediacañas" de la unión del piso con las paredes, pero son permisivos con los estándares que de manera fundamental rigen la eficiencia del servicio, como son el talento humano médico y de enfermería.

En consecuencia la medicina crítica se ha convertido en la puerta de entrada institucional al tercer y cuarto nivel de atención, es vista como un excelente negocio en la mayoría de los prestadores y para muchos ha constituido la tabla de salvación. Por lo anterior, ha tenido un enorme crecimiento en los últimos años, pero su desarrollo en términos de calidad científica y de gestión por estas razones no ha podido crecer de forma paralela. Hoy vemos muchas unidades de cuidado intensivo atendidas por "improvisados" intensivistas llenos de buenas intenciones, como haciendo intentos desesperados por aprender una compleja profesión sobre la marcha, con base en publicaciones escritas en idioma foráneo, bajo la directriz de un jefe que se

Jefe de la Unidad de Cuidado Intensivo Adultos. Profesor Titular Fundación Universitaria de Ciencias de la Salud, Hospital de San José, Bogotá D.C., Colombia. autodenomina experto y que se asoma a la unidad cuando sus múltiples ocupaciones "le dejan un tiempito", pero con la seguridad engañosa de tener cobertura "idónea" las 24 horas del día, con lo que al menos suple la responsabilidad legal y revisa la facturación.

Por su breve trayectoria en el país el cuidado intensivo carece de programas de formación suficientes en la actualidad y además el sistema desestimula con sus normas, permitiendo que nuestra profesión por falta de especialistas la ejerza personal de otras áreas de la salud dizque con experiencia en la misma. ¿Cúal será la sorpresa de nuestros dirigentes cuando de manera angustiosa escuchen de su médico tratante la voz de aliento y tranquilidad porque ya ha tenido la oportunidad de tratar dos o tres eventos similares al que le aqueja?

De otro lado, nuestra actividad gremial se mueve a tumbos por los caminos en ocasiones de la vanidad, el protagonismo personal y ía distancia de la lamentable realidad que vivimos en lo laboral, lo profesional, lo personal y por qué no decir, de lo ético. Nuestros líderes, algunos como los de cal y canto del famoso Nietche, se enfrascan en las peroratas idiomáticas de la planeación estratégica, alejándose de la realidad y desconociendo que la estructura formal y la adecuada experiencia, ganada desde los principios de la formación académica, son los pilares sobre los que se originan proyectos serios y de calidad.

El momento es coyuntural, pero los que tenemos la responsabilidad de construir el futuro de nuestra profesión tenemos que, como en las embarcaciones al garete, retomar el timonel con decisión, acierto y fidelidad con las convicciones que con base en esfuerzo y sacrificio hemos elaborado a través del pincel de la experiencia. Es así como se hace necesario abrir el debate, centrarlo en los objetivos de calidad, divulgarlo en el medio, construir y reforzar la formación académica y propiciar porque nuestros dirigentes entiendan que en este sector debemos esforzarnos de manera ejemplar, para que los proyectos de gestión tengan la sana y ética alternativa de poder atender nuestros congéneres como si fueran nuestros padres. 